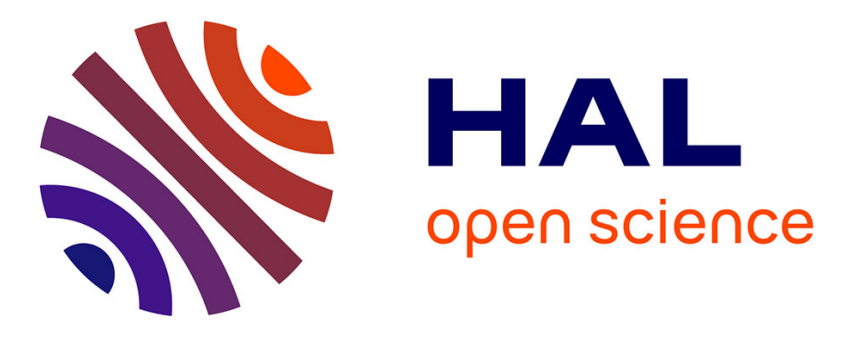

\title{
Surface and Epitaxial Stresses on Supported Metal Clusters
}

\author{
Rémi Lazzari, Jacek Goniakowski, Gregory Cabailh, Rémi Cavallotti, Nicolas \\ Trcera, Pierre Lagarde, Jacques Jupille
}

\section{- To cite this version:}

Rémi Lazzari, Jacek Goniakowski, Gregory Cabailh, Rémi Cavallotti, Nicolas Trcera, et al.. Surface and Epitaxial Stresses on Supported Metal Clusters. Nano Letters, 2016, 16 (4), pp.2574 - 2579. 10.1021/acs.nanolett.6b00143 . hal-01442816

\section{HAL Id: hal-01442816 https://hal.science/hal-01442816}

Submitted on 11 May 2020

HAL is a multi-disciplinary open access archive for the deposit and dissemination of scientific research documents, whether they are published or not. The documents may come from teaching and research institutions in France or abroad, or from public or private research centers.
L'archive ouverte pluridisciplinaire HAL, est destinée au dépôt et à la diffusion de documents scientifiques de niveau recherche, publiés ou non, émanant des établissements d'enseignement et de recherche français ou étrangers, des laboratoires publics ou privés. 


\title{
Surface and epitaxial stresses on supported metal
}

\section{clusters}

\author{
Rémi Lazzari, ${ }^{*}, \dagger$ Jacek Goniakowski, ${ }^{\dagger}$ Gregory Cabailh, ${ }^{\dagger}$ Rémi Cavallotti, $^{\dagger}$ \\ Nicolas Trcera, ${ }^{\ddagger}$ Pierre Lagarde, ${ }^{\ddagger}$ and Jacques Jupille ${ }^{\dagger}$
}

Sorbonne Universités, UPMC Univ Paris 06, CNRS UMR 7588, Institut des NanoSciences de Paris, F-75005 Paris, France, and Synchrotron SOLEIL, L'Orme des Merisiers, St-Aubin, BP48, F-91192 Gif sur Yvette, France

E-mail: remi.lazzari@insp.jussieu.fr

\begin{abstract}
Surface stress and energy are basic quantities in the Gibbsian formulation of the thermodynamic description of surfaces ${ }^{1-3}$ which is central in the formation and longterm behaviour of materials at nanoscale. However, their size-dependence is a puzzling issue. It is even unclear whether they decrease ${ }^{4-6}$ or increase $^{7,8}$ with decreasing particle size. In addition, for a given metal, estimates often span over an order of magnitude, far apart from bulk data, which, in the absence of any explicit size-dependence rule, escapes understanding. Here, we combine X-ray absorption and nanoplasmonics data with atomistic simulation to describe $\alpha-\mathrm{Al}_{2} \mathrm{O}_{3}(0001)$-supported silver particles. By comparison to $\mathrm{MgO}(001)$-supported ${ }^{9}$ and embedded ${ }^{10}$ silver, we distinguish epitaxial and surface stress. The latter is shown to dominate above $3 \mathrm{~nm}$ in size. Since the observation mostly relies on surface/bulk ratio, a metal-independent picture emerges that
\end{abstract}

\footnotetext{
*To whom correspondence should be addressed

†Sorbonne Universités, UPMC Univ Paris 06, CNRS UMR 7588, Institut des NanoSciences de Paris, F-75005 Paris, France

${ }_{\ddagger}^{\ddagger}$ Synchrotron SOLEIL, L’Orme des Merisiers, St-Aubin, BP48, F-91192 Gif sur Yvette, France
} 
is expected to have far-reaching consequences for the understanding of the energetics of nanoparticles.

Surface energy, which is the reversible work required to create a surface unit area, determines the orientation of macroscopic surfaces. Surface stress, which is the reversible work per unit area needed to elastically stretch a pre-existing surface, drives surface reconstruction. ${ }^{11}$ These two parameters control the basic phenomena, such as growth, epitaxy and adhesion, which rule the growth of thin films and nanoparticles. ${ }^{2,3}$ Their knowledge is a prerequisite to produce nanostructures with positive/negative curvature for the countless applications where they are involved. ${ }^{12}$ Surface energetics controls the synthesis of metal nanoparticles in catalysts and is pivotal to model their long-term sintering. ${ }^{7}$ It determines the behavior of nanoparticles in contact with the environment as in the case of biological fluids with formation of biomolecular coronas ${ }^{13}$ and it provides the driving force for generating templated arrays of nanoparticles that are used for sensors, growth of nanotubes or nanowires and electrical memory devices. ${ }^{14}$ The increase in surface-to-bulk atom ratio results in size-dependent equilibrium shapes, ${ }^{15}$ evaporation ${ }^{16,17}$ and sintering rates, ${ }^{7,8,18}$ as featured by the well-known Gibbs-Thompson, Laplace-Young and Kelvin equations, all relying on particle diameter, a general basis for description of materials at the scale of the nanometer. However, an issue which is not laid down by those formulae is the size-dependence of the surface energy and stress themselves. The point is utterly controversial since it still remains unclear in which sense they vary with decreasing particle size ${ }^{4-8}$ and whether the same type of behaviour applies to all materials. ${ }^{19}$ In addition, dramatic discrepancies are observed even between data that show similar trends. For example, values of surface stress determined on the basis

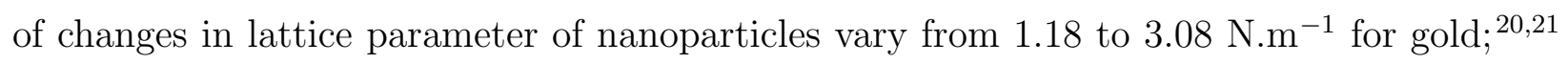
surface stress is found close to zero for copper ${ }^{22}$ and as high as $6.0 \mathrm{~N} . \mathrm{m}^{-1}$ for palladium, ${ }^{23}$

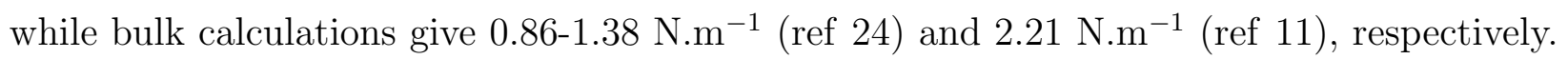
As for the much studied silver particles, focus of the present work, experimental values of

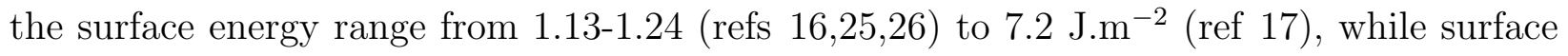


stress is found between 1.42 (refs 25,27) and 6.3-6.4 N.m ${ }^{-1}$ (refs 28,29). In contrast, theory predicts constant surface energy and stress for silver particles down to $2 \mathrm{~nm}$ in diameter and a slight increase of these parameters as a function of size for smaller clusters. ${ }^{30}$ The huge discrepancies between the different estimates up to an order of magnitude for both surface energy $^{11,16,17,24,25,30,31}$ and surface stress ${ }^{10,11,24,25,27-30}$ of silver are troubling, since they are pivotal quantities in the basic description of solid materials at the nanoscale. Moreover, while measurements regarding nanoparticles often strongly depart from bulk results, the absence of experimental evidence on the size-dependence they obey prevents the understanding of the physical origin of the observed differences.

The blurred landscape of the size-dependent energetics in nanoparticles points to a lack of relevant methods to determine morphologies and their links with properties. ${ }^{32}$ This is particularly true for supported particles, for which the interaction with the support additionally modifies the characteristics of surface stress and energy and impacts the size-driven behaviour. The present work reports on a joint approach by ultra-high vacuum (UHV) experiments and semi-empirical simulations on structure and morphology characteristics of $\alpha-\mathrm{Al}_{2} \mathrm{O}_{3}(0001)$-supported silver nanoparticles as a function of their size. Experiments involve Extended X-ray Absorption Fine Structure (EXAFS) and plasmonics-based Surface Differential Reflectivity Spectroscopy (SDRS) to determine interatomic distances and particle morphology, respectively. Simulations rely on first-principles calculations for model silver/alumina interfaces and on atomistic calculations of supported nanoparticles based on interatomic potentials. Methods are presented as supplementary information. First, by confronting measurements of the metal-substrate distance and results of first principles calculations, the structural characteristics of the silver-alumina interface are determined. Based on this knowledge and on atomistic calculations on supported clusters, the measured sizedependence of particle morphology and shape is firmly emphasized. Finally, by extending the analysis to the case of previously studied $\mathrm{MgO}(001)$-supported ${ }^{9}$ and Ar-embedded ${ }^{10}$ sil- 
ver particles, silver surface and epitaxial stresses are unambiguously distinguished.

The close similarity of the EXAFS edge structures with reference spectra of metallic silver indicates that silver is in its metallic form rather than chemically bound to surface oxygen atoms, in line with the predicted weak interaction between silver and Al-terminated alumina surface. ${ }^{33,34}$ At normal incidence, the Fourier transform of the fine structure function $k^{3} \chi(k)$ (Figure 1-a) shows an unique peak around $2.9 \AA$ attributed to the nearest $\mathrm{Ag}$ - $\mathrm{Ag}$ neighbour distance. For the thinnest Ag films studied herein, fits of EXAFS spectra recorded at $60^{\circ}$ offnormal to probe the silver-oxide interface reveal an additional component. It demonstrates the existence of a defined $\mathrm{Ag}$ site at the interface and a well defined epitaxy. It is best accounted for by an Ag-O bond with an estimated $d_{A g-O}=2.65 \pm 0.06 \AA$. Consistent with the often observed fcc(111)/ $\alpha-\mathrm{Al}_{2} \mathrm{O}_{3}(0001)$ epitaxy, ${ }^{35-37}$ this observation is also of a general interest since computational results are conflicting. In the case of silver, regardless the computational approach, various hollow surface sites are favoured over atop oxygen ones, but turn out to produce similar binding energies..$^{33,38-40}$ The present dispersion-corrected DFT calculations in the limit of isolated Ag ad-atoms show a well-pronounced preference for the hollow $\mathrm{Al}_{3}$ site $\left(d_{A g-O}=2.59 \AA\right)$, which corresponds to the prolongation of the corundum lattice (Figure 1-b and c-insets). This site remains favoured $\left(d_{A g-O}=2.67 \AA\right)$ also at the simulated multilayer coverage (Figure 1-c).

The existence of favoured interface sites suggests a compression of the silver lattice induced by the negative $\mathrm{Ag} / \alpha-\mathrm{Al}_{2} \mathrm{O}_{3}$ misfit $\left(d_{\mathrm{Al}_{2} \mathrm{O}_{3}}-d_{A g}\right) / d_{\mathrm{Al}_{2} \mathrm{O}_{3}}=-5.1 \%$. To test this hypothesis, the morphology and structure of the silver particles are now analysed. Series of SDRS experiments were performed during the growth of the $\mathrm{Ag} / \alpha-\mathrm{Al}_{2} \mathrm{O}_{3}(0001)$ films. The almost isotropic silver clusters ${ }^{41}$ being represented by truncated spheres, their size and wetting angle (derived from aspect ratios), were determined by fitting the optical data. ${ }^{42}$ As the size of silver particles increases, the contact angle $\theta_{c}$ increases steeply from $105^{\circ}$ to $145^{\circ}$ and 
passes through a maximum for particles of $\sim 5-6 \mathrm{~nm}$ in size (Figure 2-a), in agreement with previous observations. ${ }^{43,44}$ The adhesion energy determined by means of the Young-Dupré formula $E_{a d h}=\gamma_{A g}\left(1+\cos \theta_{c}\right)$ with $\gamma_{A g}=1.24 \mathrm{~J}_{\mathrm{J}}{ }^{-2}$ (ref 31) decreases from 0.9 to $0.2{\mathrm{~J} . \mathrm{m}^{-2}}^{-2}$ and passes through a minimum for particles of $\sim 5-6 \mathrm{~nm}$ (Figure 2-a). For larger clusters, it has been previously shown that the adhesion energy tends toward $0.48 \mathrm{~J} . \mathrm{m}^{-2}$ (wetting angle of $\left.125-130^{\circ}\right) .{ }^{44}$ The change in wetting angle is paralleled by a progressive increase in the Ag-Ag distance $d_{A g}$ with increasing size, as evidenced by EXAFS (Figure 2-b). Most importantly, the Ag-Ag distance is seen to abruptly increase for particles of $\sim 5-6 \mathrm{~nm}$ in size, in coincidence with the maximum of the wetting angle, prior to reaching the bulk $\mathrm{Ag}$ value (Figure 2- b). The full details of the SDRS measurements are also reported in the supporting information. The atomistic simulations nicely parallel the experiments. While a precise quantitative comparison may not be possible due to the semi-empirical character of interatomic potentials, the overall progressive increase of the $\mathrm{Ag}-\mathrm{Ag}$ interface distance as a function of particle size and its sudden increase (Figures 2 -b,d) at the size corresponding to the minimum of adhesion energy are well reproduced (Figures 2 -a,c). Moreover, through a mapping of Ag-alumina interaction at atoms in direct contact with the oxide substrate (Figure 2-inset), simulations give a direct hint on the origin of the observed behaviour. For small Ag particles, a contracted distance $d_{A g} \sim d_{A_{2} O_{3}}$, makes interfacial Ag atoms occupy favourable $\mathrm{Al}_{3}$ sites (Figure 2-inset) giving rise to a well defined $\mathrm{Ag}$-O distance at grazing incidence. At large sizes, with $d_{A g}$ approaching the bulk Ag value, misfit dislocations appear and manifest themselves by the appearance of zones of bad coincidence with no $\mathrm{Ag}$ in atop $\mathrm{Al}_{3}$ sites (Figure 2-inset). At the critical size, the in-plane compression is released by the introduction of first misfit dislocations, which produces the minimum of adhesion energy and the abrupt relaxation of the silver parameter (Figures 2-c and -d). The critical size of $\sim 7 \mathrm{~nm}$ is somewhat larger compared to the estimation derived from the Vernier rule $d_{A g} d_{A l_{2} O_{3}} /\left(d_{A g}-d_{A l_{2} O_{3}}\right)=5.5 \mathrm{~nm}^{45}$ due to finite particle size. It is stressed that the behaviour described in the present paragraph requires the existence of defined sites for silver, 
in agreement with the above discussion on the Ag-oxide interface.

However, the reason of the change in parameter $d_{A g}$ observed during the growth of the Ag clusters (Figure 2-b) escapes understanding since it combines contributions from both surface and epitaxial stresses. The surface stress $f$ of an unsupported spherical cluster can be expressed as a function of the relative change in lattice parameter $\Delta d_{A g}$ by the following relationship ${ }^{1,20}$ that is derived from the expression of the Laplace pressure ${ }^{2}$ for a solid particle $4 f / D$ :

$$
f=\frac{3}{4} \frac{\Delta d_{A g}}{d_{A g(b u l k)}} \frac{D}{K}
$$

where $d_{A g(b u l k)}$ is the bulk parameter, $D$ the particle diameter and $K$ the material compressibility. Thus, if driven by the surface stress alone and considering the latter constant, the parameter $d_{A g}$ is expected to vary linearly as a function of the inverse of the diameter, the $\mathrm{y}$ intercept corresponding to $d_{A g(b u l k)}$ and the slope giving the value of the surface stress $f$. As to identify the surface and epitaxial contributions, the present results for $\mathrm{Ag} / \alpha-\mathrm{Al}_{2} \mathrm{O}_{3}(0001)$ characterized by a negative misfit have been complemented with data on the previously studied $\mathrm{Ag} / \mathrm{MgO}(001)$, with a positive $+3 \%$ lattice misfit, ${ }^{9}$ and with EXAFS results on Ar-embeded Ag clusters. ${ }^{10}$ As it can be seen in Figure 3, the two data sets recorded on oxide-supported particles show two regimes, below and above $\sim 3 \mathrm{~nm}$ particle size. Above $\sim 3 \mathrm{~nm}$ in size, changes in the $d_{A g}$ parameter can be represented by a straight line with a slope $f=2.2 \pm 0.4 \mathrm{~N} . \mathrm{m}^{-1}$, which corresponds to the surface stress. Here, the sudden increase in $d_{A g}$ (Figure 2-d) is negligible with respect to the average value of the parameter. This estimation nicely agrees with the value of $2.3 \mathrm{~N} . \mathrm{m}^{-1}$ obtained for Ar-embedded clusters. ${ }^{10}$ The overall agreement between the three sets of data clearly demonstrates that the $d_{A g}$ average distance is only marginally affected by the epitaxy and that the size-dependence of the lattice parameter of large silver clusters is the same, no matter whether they are unsupported or supported on one or the other substrate. The dominant effect of the surface stress over the epitaxy is further evidenced by the isotropic contraction of the $\mathrm{Ag} / \alpha-\mathrm{Al}_{2} \mathrm{O}_{3}(0001)$ lattice 
that is revealed by the similarity of the out-of-plane and in-plane Ag-Ag distances extracted from normal and grazing absorption spectra for particles larger than $3 \mathrm{~nm}$ (Supporting Information) .

In contrast, values of the silver parameter strongly deviate from the linear behaviour for clusters smaller than $\sim 3 \mathrm{~nm}$ (Figure 3 ). The distance $d_{A g}$ decreases for particles supported on $\alpha-\mathrm{Al}_{2} \mathrm{O}_{3}(0001)$, and increases for those on $\mathrm{MgO}(001)$, to improve the lattice matching at the interface. A qualitatively similar behaviour also has been observed for $\mathrm{Pt} / \mathrm{MgO}(001) .{ }^{46}$ The $\mathrm{Ag} / \mathrm{MgO}(001)$ system deserves an additional comment. In silver particles of $\sim 2 \mathrm{~nm}$ in size, the interface $\mathrm{Ag}$ atoms tend to sit atop surface oxygen atoms ${ }^{47,48}$ and the $d_{A g}$ parameter almost fits that of $\mathrm{MgO}$, although the $\mathrm{Ag} / \mathrm{MgO}(001)$ film does not become fully pseudomorphic. ${ }^{49}$ However, for clusters smaller than $1.5 \mathrm{~nm}, d_{A g}$ steeply decreases to reach values that lie close to the $f=2.2{\mathrm{~N} . \mathrm{m}^{-1}}^{-1 i n e}$. This may suggest that, due to the weak Ag-MgO bonding, the epitaxial stress gives a significant contribution only when a dominant proportion of interface $\mathrm{Ag}$ atoms are in their favoured atop oxygen sites. ${ }^{9}$

Within experimental errors, the surface stress value $f=2.2 \pm 0.4 \mathrm{~N}^{-\mathrm{m}^{-1}}$ obtained for particles larger than $3 \mathrm{~nm}$ is independent of cluster size and, as shown by the fair comparison with the analysis of Ar-embedded Ag clusters, ${ }^{10}$ not affected by the presence of a support. The result is all the more robust that it is in line with cluster calculations which predict a constant value of the surface stress as a function of size for particles down to $2 \mathrm{~nm}$ in size. ${ }^{30}$ As for the value of the surface stress, the present measurement clearly disagrees with data relying on the (111) diffraction peak positions (4.7-6.4 N.m ${ }^{-1}$ - refs 28,29), which were already questioned on the basis of the way in which data are analysed. ${ }^{27}$ In contrast, the value

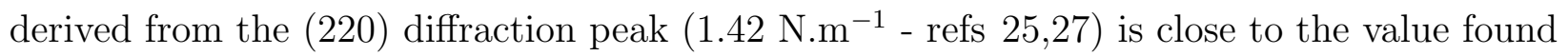
herein, although lower by about $30 \%$. The observed differences do not seem to stem from the experimental accuracy since measurements performed by a given method show a fair 


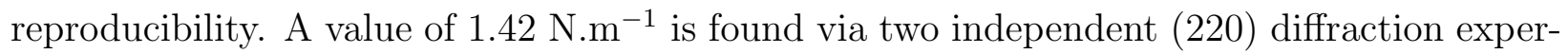
iments $^{25,27}$ while EXAFS leads to $2.2-2.3 \mathrm{~N}^{-\mathrm{m}^{-1}}$ in conditions that strongly differ (present work and refs 10 and 9). Indeed, EXAFS is a local probe accounting for all interatomic distances whereas diffraction probes the ordered fraction of clusters along a given crystallographic direction. Therefore, the discrepancy between EXAFS and diffraction data could be indicative of the limits of the description of the relative change in lattice parameter in very small particles.

Regarding silver, it is worth noting that calculated values of surface energy are systematically lower than calculated values of surface stress. ${ }^{11,24,30}$ On the basis of the Shuttleworth equation $f=\gamma+\delta \gamma / \delta \epsilon,{ }^{50}$ where $\gamma$ is the surface energy and $\epsilon$ the elastic strain, such trend means that the surface stress of metals should be tensile ${ }^{3}$ so that $\delta \gamma / \delta \epsilon>0$. Therefore, a likely upper limit for the surface energy of silver nanoparticles deduced from the present

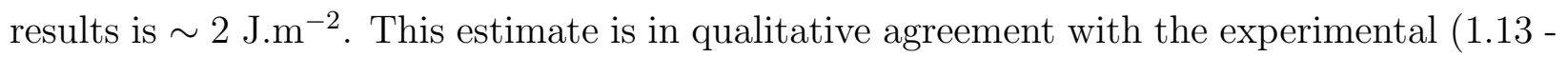

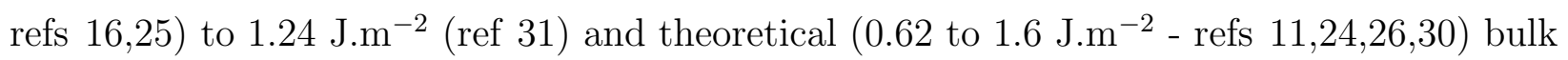
values. It discards the much higher value of $7.2 \mathrm{J.m}^{-2}$ found for the surface energy of silver on the basis of evaporation rates of nanoparticles. ${ }^{17}$

To summarise, morphology and structure of alumina-supported silver nanoparticles have been studied by plasmonics and X-ray absorption edges, with a support from first-principles and semi-empirical calculations. The size-dependence of the particle lattice parameter and of its adhesion energy for clusters ranging between 1 and $7 \mathrm{~nm}$ has been rationalized and linked to the existence of a preferential site for Ag atoms at the Ag/alumina interface. By comparison with $\mathrm{Ag} / \mathrm{MgO}(001)$ and Ar-embedded $\mathrm{Ag}$ clusters, it has been shown that for particles less than $3 \mathrm{~nm}$ in size, the lattice parameter of silver becomes dictated by the epitaxial stress and either expands or shrinks depending whether the metal-oxide misfit is positive or negative. In contrast, for diameter larger than $3 \mathrm{~nm}$, no matter whether silver 
clusters are supported or unsupported, a robust size-independent value of silver surface stress

$f=2.2 \mathrm{~N} . \mathrm{m}^{-1}$ has been determined. Since the observed properties are primarily dependent on the atomic surface/bulk ratio and not the nature of the metal under study, it is suggested that they may be generalized to any metal particles.

\section{Supporting information}

The supporting information is available free of charge on the ACS publication web site. (I) Experiments description, (II) Numerical simulations, (III) EXAFS analysis, (IV) SDRS analysis

\section{Author contribution}

R. L. conducted the optical measurements and analysis and leaded the synchrotron beamtimes. J. G. and R. C. did the ab initio calculations of model interfaces and J.G. performed molecular dynamics simulations of supported clusters. G. C. participated to the synchrotron experiments. N. T. and P. L. carried out the EXAFS measurements and analysis. J. J. wrote the initial manuscript draft and all authors discussed in depth the results and contributed to the final manuscript. R. L. and J. J. designed the research approach.

Correspondence and requests for materials should be addressed to R.L. The authors declare no competing nancial interest.

\section{Acknowledgements}

This work benefited from the technical support of D. Roy (SOLEIL), S. Chenot (INSP) and H. Cruguel (INSP). R. Cavallotti PhD thesis was supported by a CIFRE grant form Arcelor-Mittal company. 


\section{Notes and References}

(1) Vermaak, J. S.; Mays, S. W.; Kuhlmann-Wilsdorf, D. Surf. Sci. 1968, 12, 128.

(2) Cammarata, C. R. Progr. Surf. Sci. 1994, 46, 1.

(3) Ibach, H. Surf. Sci. Rep. 1997, 29, 193-263.

(4) Zhang, H.; Penn, R. L.; Hamers, R. J.; Banfield, J. F. J. Phys. Chem. B 1999, 103, 4656.

(5) Lu, H. M.; Jiang, Q. J. Phys. Chem. B 2004, 108, 5117.

(6) Ouyang, G.; Tan, X.; Yang, G. Phys. Rev. B. 2006, 74, 195408.

(7) Campbell, C. T.; Parker, S. C.; Starr, D. E. Science 2002, 298, 811.

(8) Parker, S. C.; Campbell, C. T. Phys. Rev. B 2007, 75, 035430.

(9) Lagarde, P.; Colonna, S.; Flank, A.; Jupille, J. Surf. Sci. 2003, 524, 102.

(10) Montano, P.; Schulze, W.; Tesche, B.; Shenoy, G. K.; Morrison, T. I. Phys. Rev. B 1984, 30, 672-677.

(11) (a) Fiorentini, V.; Methfessel, M.; Scheffler, M. Phys. Rev. Lett. 1993, 71, 1052-1054;

(b) Fiorentini, V.; Methfessel, M.; Scheffler, M. Phys. Rev. Lett. 1998, 81, 2184.

(12) Ouyang, G.; Wang, C. X.; Yang, G. W. Chem. Rev. 2009, 109, 4221-4247.

(13) Monopoli, M. P.; Åberg, C.; Salvati, A.; Dawson, K. A. Nature Nanotechnology 2012, 7, 779-786.

(14) Thompson, C. V. Annu. Rev. Mater. Res. 2012, 42, 399-434.

(15) Patala, S.; Marks, L. D.; Olvera de la Cruz, M. J. Chem. Phys. Lett. 2013, 4, 3089.

(16) Blackman, M.; Lisgarten, N. D.; Skinner, L. M. Nature 1968, 217, 1245. 
(17) Nanda, K. K.; Maisels, A.; Kruis, F. E.; Fissan, H.; Stappert, S. Phys. Rev. Lett. 2003, $91,106102$.

(18) Wynblatt, P.; Gjostein, N. A. Acta Metall 1976, 24, 1165.

(19) Diehm, P.; Ágoston, P.; Albe, K. Chem. Phys. Chem. 2012, 13, 2443.

(20) Mays, C. W.; Vermaak, J. S.; Kuhlmann-Wilsdorf, D. Surf. Sci. 1968, 12, 134-140.

(21) Solliard, C.; Flueli, M. Surf. Sci. 1985, 156, 487.

(22) Wasserman, H.-J.; Vermaak, J. S. Surf. Sci. 1972, 32, 168.

(23) Lamber, R.; Wetjen, S.; Jaeger, N. I. Phys. Rev. B 1995, 51, 10968.

(24) Gumbsch, P.; Daw, M. S. Phys. Rev. B 1991, 44, 3934.

(25) Ruud, J. A.; Witvrouw, A.; Spaepen, F. J. Appl. Phys. 1993, 74, 2517.

(26) Vitos, L.; Ruban, A.; Skriver, H.; Kollár, J. Surf. Sci. 1998, 411, 186.

(27) Wasserman, H.; Vermaak, J. Surf. Sci. 1970, 22, 164-172.

(28) Berry, C. R. Phys. Rev. B 1952, 88, 596.

(29) Hofmeister, H.; Thiel, S.; Dubiel, M.; Schurig, E. Appl. Phys. Lett. 1997, 70, 1694.

(30) Medasani, B.; Park, Y.; Vasiliev, I. Phys. Rev. B 2007, 75, 235436-.

(31) Tyson, W.; Miller, W. Surf. Sci. 1977, 62, 267.

(32) Grassian, V. H. J. Phys. Chem. C 2008, 112, 18303.

(33) Bogicevic, A.; Jennison, D. R. Phys. Rev. Lett. 1999, 82, 4050.

(34) Cavallotti, R.; Goniakowski, J.; Lazzari, R.; Jupille, J.; Koltsov, A.; Loison, D. J. Phys. Chem. C 2014, 118, 13578-13589. 
(35) Lairson, B. M.; Visokay, M. R.; Sinclair, R.; Hagstrom, S.; Clemens, B. M. Appl. Phys. Lett. 1992, 61, 1390.

(36) Dehm, G.; Ruhle, M.; Ding, G.; Raj, R. Philos. Mag. B 1995, r1, 1111.

(37) Curiotto, S.; Chien, H.; Meltzman, H.; Wynblatt, P.; Rohrer, G. S.; Kaplan, W. D.; Chatain, D. Acta Materialia 2011, 59, 5320.

(38) Zhang, W.; Smith, J. R. Phys. Rev. Lett. 2000, 85, 3225.

(39) Zhukovskii, Y.; Kotomina, E.; Herschendb, B.; Hermanssonb, K.; Jacobs, P. Surf. Sci. 2002, 513, 343-358.

(40) Meyer, R.; Ge, Q.; Lockemeyer, J.; Yeates, R.; Lemanski, M.; Reinalda, D.; Neurock, M. Surf. Sci. 2007, 601, 134-145.

(41) Stankic, A.; Cortes-Huerto, R.; Crivat, N.; Demaille, D.; Goniakowski, J.; Jupille, J. Nanoscale 2013, 5, 2448-2453.

(42) Lazzari, R.; Simonsen, I. Thin Solid Films 2002, 419, 124-136.

(43) Lazzari, R.; Jupille, J. Nanotechnology 2011, 22, 445703.

(44) Lazzari, R.; Jupille, J. Nanotechnology 2012, 23, 135707-135720.

(45) The Vernier value is half that found in ref 44 on the basis of the size of the unit cell of the alumina surface since the present calculation is done instead by considering that all $\mathrm{h}$ sites are equivalent for $\mathrm{Ag}$ adsorption.

(46) Olander, J.; Lazzari, R.; Mangili, B.; Goniakowski, J.; Renaud, G.; Jupille, J. Phys. Rev. B 2007, 76, 075409.

(47) Flank, A.; Delaunay, R.; Lagarde, P.; Pompa, M.; Jupille, J. Phys. Rev.B 1996, 53, R1737. 
(48) Ferrando, R.; Rossi, G.; Levi, A.; Kuntova, Z.; Nita, F.; Jelea, A.; Mottet, C.; Barcaro, G.; Fortunelli, A.; Goniakowski, J. J. Chem. Phys. 2009, 130, 174702.

(49) Robach, O.; Renaud, G.; Barbier, A. Phys. Rev. B 1999, 60, 5858-5871.

(50) Shuttleworth, R. Proc. Phys. Soc. A 1950, 63, 444. 

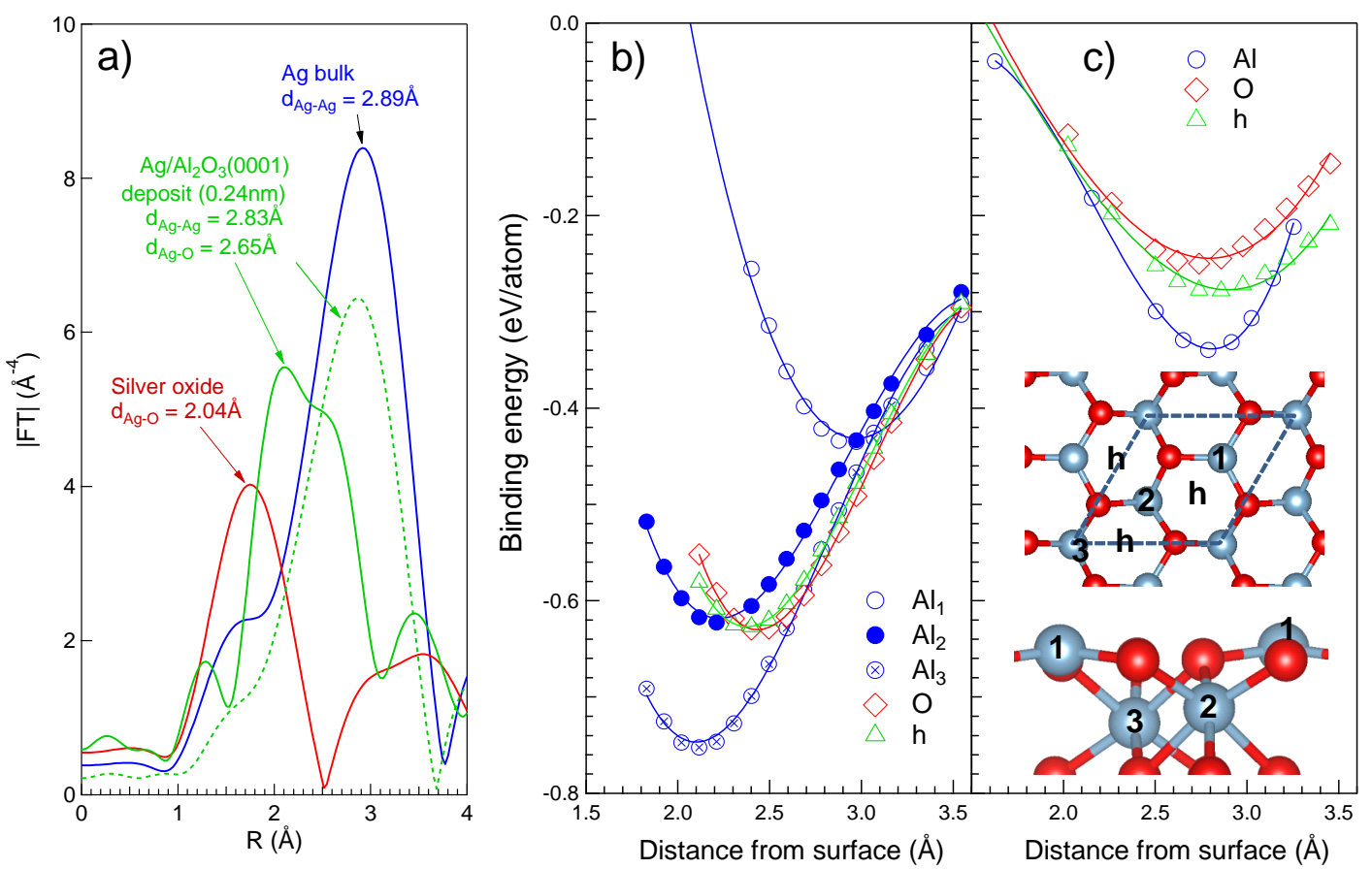

Figure 1: (Color online). EXAFS analysis and first-principle results on $\mathrm{Ag} / \alpha-\mathrm{Al}_{2} \mathrm{O}_{3}(0001)$ : a) Magnitude of the Fourier transform of the fine structure function $k^{3} \chi(k)$ corresponding to a $0.24 \mathrm{~nm}$ thick deposit of $\mathrm{Ag} / \mathrm{Al}_{2} \mathrm{O}_{3}(0001)$ (green curves) (see supporting information Figure SI-1-b). At normal incidence (dotted green line), a unique component is evidenced which corresponds to the Ag-Ag distance. At grazing incidence (green line), an extra component appears which is assigned to the Ag-O distance. The analysis of silver oxide (red line) and bulk silver (blue line) are shown for comparison. b) Binding energy of isolated atoms of $\mathrm{Ag}$ on $\alpha-\mathrm{Al}_{2} \mathrm{O}_{3}(0001)$ as a function of $\mathrm{Ag}$-oxide distance for different sites of the alumina surface as defined in the inset. c) Average binding energy (per interfacial Ag) of a multi-layer $\mathrm{Ag}$ deposit at different lattice registry with the substrate. The insets show a representation of the $\alpha-\mathrm{Al}_{2} \mathrm{O}_{3}(0001)$ surface (top : top view; bottom: side view). Various $\mathrm{Al}(1,2,3$; blue balls) and hollow (h) sites are explicitly indicated; $\mathrm{O}$ are represented by red balls. 

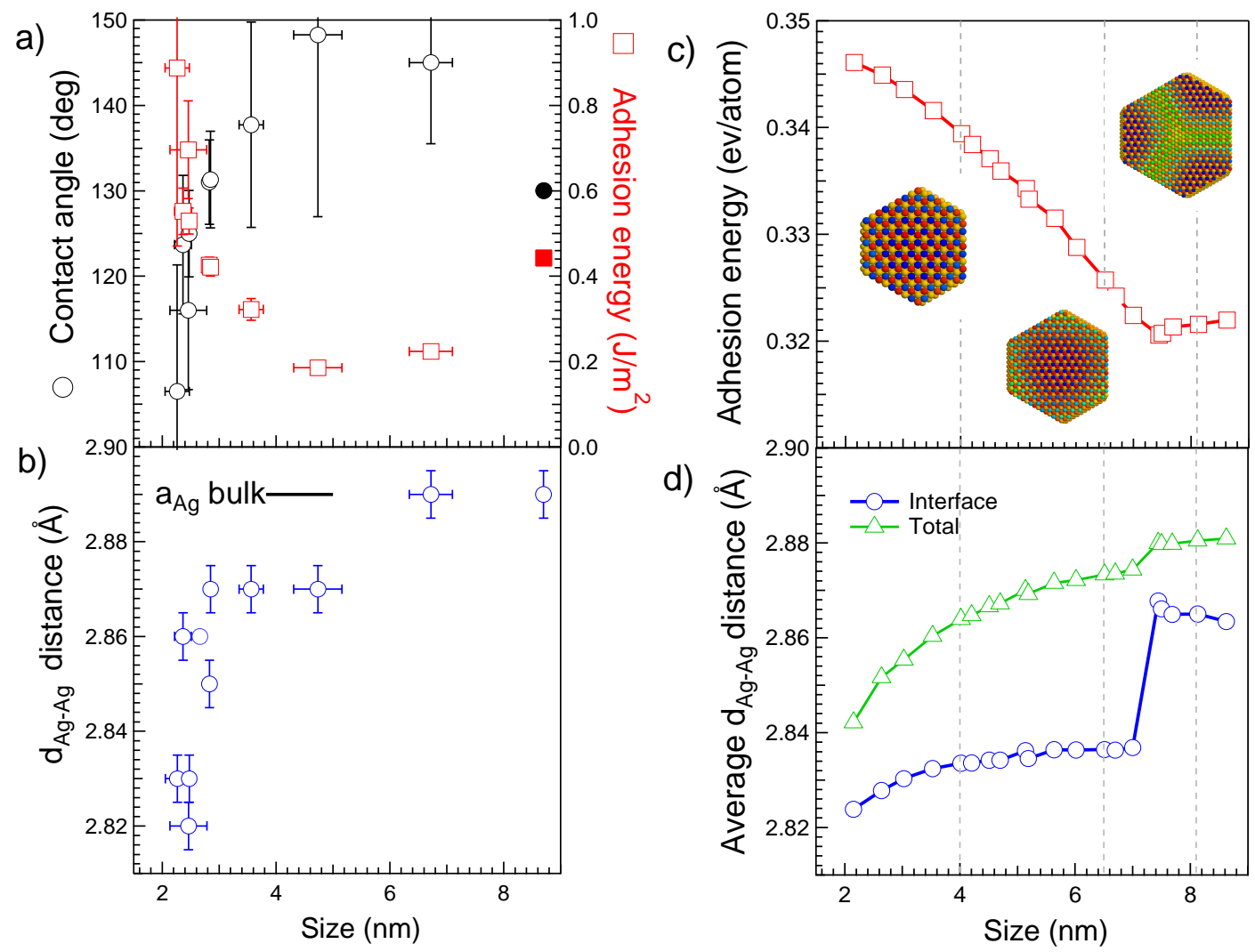

Figure 2: (Color online). Ag clusters on $\alpha-\mathrm{Al}_{2} \mathrm{O}_{3}(0001)$ - Experiments: a) Wetting angle, as determined by SDRS measurements, and values of adhesion energy calculated by the Young-Dupré formula; the morphology at a size above $8 \mathrm{~nm}$ was extrapolated from previous measurements $^{44}$ (see supporting information) and shown by filled symbols; b) Ag-Ag distance determined by EXAFS measurements as a function of the cluster diameter. Numerical simulations: c) adhesion energy as a function of cluster size; The insets shows three representations of cluster interface correspond to the dotted lines in figure. Colour code corresponds to Ag-alumina interaction strength: blue-strong $\left(\mathrm{Al}_{3}\right.$ site), green-moderate, red-weak $\left(\mathrm{Al}_{1}\right.$ site); d) Plot of the behaviour of the average in plane and total Ag-Ag distance versus the cluster size. 


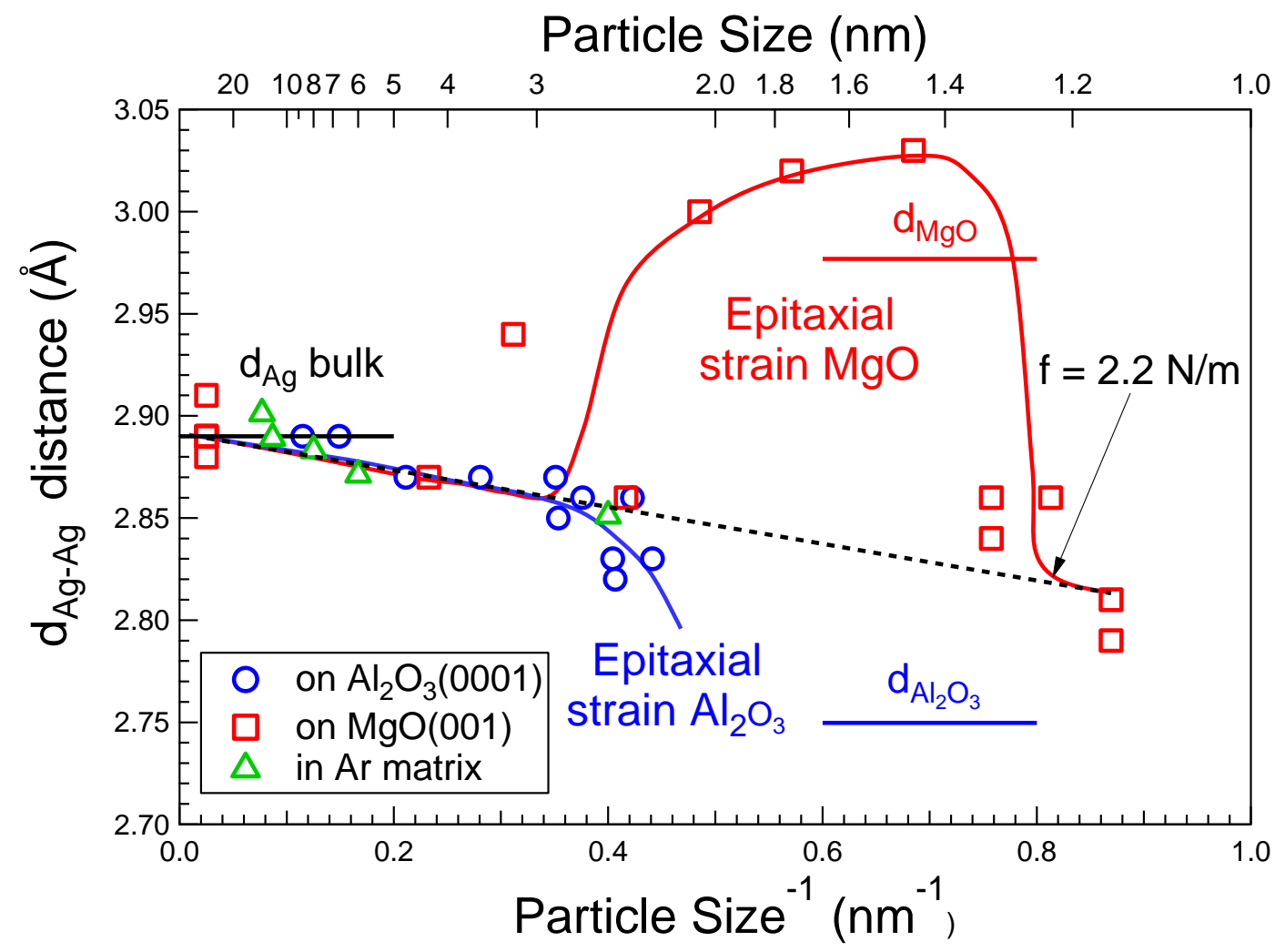

Figure 3: (Color online). Ag parameter vs the inverse of the particle diameter $\left(D^{-1}\right): \mathrm{Ag} / \alpha$ $\mathrm{Al}_{2} \mathrm{O}_{3}(0001)$ (blue circles), $\mathrm{Ag} / \mathrm{MgO}(001)$ (red squares), ${ }^{9}$ experiment from Montano et al. ${ }^{10}$ (green triangles, corrected to account for the difference in temperature with respect to our data). $\mathrm{Ag}, \mathrm{MgO}, \mathrm{Al}_{2} \mathrm{O}_{3}$ bulk distances are shown by horizontal lines. The slope of the dashed black line corresponding to interface stress-free data leads to a value of surface stress $f=2.2 \mathrm{~N} . \mathrm{m}^{-1}$. Deviations are due to epitaxial strain as explained in the text. 


\section{Graphical TOC Entry}

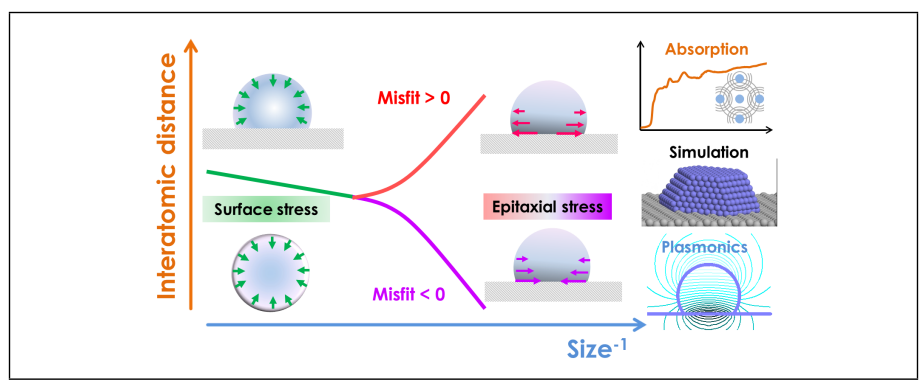

